IMAGINED CONTACT AND INTERCULTURAL COMMUNICATION

Imagined Intergroup Contact Facilitates Intercultural Communication For College Students On Academic Exchange Programs 
IMAGINED CONTACT AND INTERCULTURAL COMMUNICATION

\title{
Imagined Intergroup Contact Facilitates Intercultural Communication For College Students On Academic Exchange Programs
}

\begin{abstract}
Imagined intergroup contact (Crisp \& Turner, 2009) is a new cognitive intervention designed to improve intergroup relations. In two studies, we examined whether it could also facilitate intercultural communication among international students and host country natives engaged in a college exchange program. In Study 1, international students who had recently arrived in Italy and participated in an imagined contact session displayed increased self-disclosure toward, and improved evaluation of, host country natives. In Study 2, Italian students mentally simulated positive contact with an unknown native from the host country prior to leaving for the exchange. Results from an online questionnaire administered on their return (on average, more than seven months after the imagery task) revealed that participants who imagined contact reported spending more time with natives during the stay and enhanced outgroup evaluation, via reduced intergroup anxiety. Implications for enhancing the quality and effectiveness of college student exchange programs are discussed.
\end{abstract}

Keywords: imagined contact, international students, intercultural communication, exchange programs, intergroup relations, intergroup anxiety. 


\section{Imagined Intergroup Contact Facilitates Intercultural Communication For College Students On Academic Exchange Programs}

The context of higher education can provide a positive and supportive environment where international and home students can socially mix. However, international students report difficulties and feelings of isolation when interacting with home students (UKCOSA, 2004), a process that can negatively impact on their cultural integration (Paige, 1990; Pedersen, 1991). As such, it is perhaps not surprising that exchange students sometimes report developing negative attitudes toward host country natives over time (Klineberg \& Hull, 1979; Stroebe, Lenkert, \& Jonas, 1988) which persist after they return home (Stangor, Jonas, Stroebe, \& Hewstone, 1996). This may also depend on the fact that the salience of exchange students nation's minority status can be enhanced during the exchange period (McGuire, McGuire, Child, \& Fujioka, 1978), so that interactions with the majority (i.e., the host group) may be avoided. There is consistent evidence that international students are more likely to socialize with other international students than with host country nationals (Sigalas, 2010). Additionally, home students perceive international students to have cultural adjustment problems (Spencer-Rodgers, \& McGovern, 2002). A range of empirical and archival research demonstrates the enormous benefits to individuals of intercultural experiences (BenetMartínez, Lee, \& Leu, 2006; Simonton, 1999) - as long as individuals engage with the experience, and do not segregate themselves from the host community.

Positive previous contact experiences can improve future intergroup interactions (Hodson \& Hewstone, 2013; Pettigrew \& Tropp, 2011), also when considering the relationship between international students and host country members (Stroebe et al., 1988). In the context of intercultural communication, however, establishing positive and 
IMAGINED CONTACT AND INTERCULTURAL COMMUNICATION

meaningful face-to-face interactions between exchange students and natives can be complicated and impractical prior to students' departure or immediately after their arrival. Indeed, for many participants in these exchanges, this will be their first experience of the host culture. A practical, theoretically grounded, solution to this problem may be found in recent research developing simple, efficient and applicable cognitive interventions to the task of improving intergroup relations. One such intervention is imagined intergroup contact (Crisp \& Turner, 2009), which involves mentally simulating a social interaction with a member of the outgroup. Despite involving no actual face-to-face encounters, imagined contact has been found to elicit positive attitude change toward outgroups and to enhance future contact intentions (for recent reviews see Crisp, Husnu, Meleady, Stathi \& Turner, 2010; Crisp \& Turner, 2012; for a meta-analysis, see Miles \& Crisp, 2014). We present two studies that tested whether imagined contact metholologies could be applied to the enhancement of intercultural communication, integration and engagement on college student exchange programs. We found that imagined contact did indeed facilitate intercultural communication between international students and country natives, as shown by measures of intergroup anxiety, intergroup attitudes and self-disclosure toward the outgroup. Importantly, our studies demonstrate, for the first time, a self-reported behavioral outcome of imagined contact that spans several months subsequent to the administration of the intervention.

\section{Study 1}

In this first study, we aimed to demonstrate that imagined contact improves selfdisclosure toward, and evaluation of, host country natives among international students who just arrived in their country of destination. We focused on self-dislosure and 
evaluation because past research has demonstrated the importance of these variables as critical components of intercultural communication (Turner, Hewstone, \& Voci, 2007; Vezzali, Capozza, Giovannini, \& Stathi, 2012).

Incoming students taking part to this study encountered a positive environment at their arrival, which likely met all of Allport's (1954) conditions. First, international students were welcomed in a reception organized by the University staff in order to present University services and provide some basic information concerning college life, which was likely to raise perceptions of institutional support. Moreover, international students were welcomed by the local section of the International Exchange Erasmus Student Network, a non-profit association formed by students of the local university aimed at providing opportunities for cultural integration and self-development. Since this organization operates under the principle of students helping other students, it is likely that its activities foster perceptions of cooperation for mutual goals under status equality among international students. This supportive environment is likely to create positive conditions for intergroup contact and, thus, for the improvement of intergroup relations. Finding that imagined contact improves intergroup attitudes over and above the effects of these institutional and informal activities would represent an important confirmation for the imagined contact theory (Crisp \& Turner, 2009, 2012).

\section{Method}

\section{Participants and Procedure}

Forty international students (29 females, 2 missing) coming to Italy from eight European countries $\left(M_{\mathrm{age}}=21.95\right.$ years $)$, recruited within 3-4 weeks after their arrival, were randomly allocated to the experimental vs. control condition. ${ }^{1}$ In the experimental condition, participants were asked to imagine having a relaxed and comfortable 
IMAGINED CONTACT AND INTERCULTURAL COMMUNICATION

interaction with an Italian stranger, and to think what they would learn and how they would feel. In the control condition, participants imagined a walk along streets in Italy. In both conditions, to strenghten the efficacy of the manipulation, participants were asked to imagine the encounter from a third-person perspective (Crisp \& Husnu, 2011) and to keep eyes closed (Husnu \& Crisp, 2011), before writing a detailed description of what they imagined (Husnu \& Crisp, 2010), all techniques previously found to enhance the effects of imagined contact. After this mental simulation task, participants completed a questionnaire.

\section{Measures}

Self-disclosure toward the outgroup. A three-item measure was used $(1=$ not at all; 5 = very much) adapted from Turner et al. (2007): "Would you disclose your problems to an Italian?"; "Would you discuss intimate and personal issues with an Italian?"; "Would you disclose how are you feeling to an Italian?". Items were combined in a single index of self-disclosure toward the outgroup (alpha $=.90$ ).

Outgroup evaluation. Participants evaluated Italians on a feeling thermometer (Haddock, Zanna, \& Esses, 1993). Specifically, they were asked to express their attitude by indicating how they felt toward Italians on a scale ranging from 0 (attitude extremely unfavorable) to 100 (attitude extremely favorable); 50 was the neutral point.

\section{Results}

Outgroup evaluation was more positive in the experimental $(M=86.32)$ versus the control $(M=77.14)$ condition, $t(38)=2.67, p=.011$. Similarly, self-disclosure was higher in the experimental $(M=3.74)$ versus the control $(M=3.14)$ condition, $t(38)=$ $2.03, p=.049$. 
Table 1

\section{Study 2}

Having established the basic efficacy of our simulation task for improving selfdisclosure and intergroup attitudes, in Study 2 we aimed to evaluate the effectiveness of the intervention for improving intercultural communication on a cohort of international exchange students leaving for an exchange program. In this study we used a longitudinal design in order to evaluate the long-term effects of the intervention. College students leaving for the exchange program were asked to take part in an imagined contact session prior to their departure. They then completed a questionnaire soon after their return to their home country, in order to evaluate the effectiveness of the intervention (compared to a control group of exchange students who did not take part in the intervention). The key dependent variables were a self-reported behavioral measure of self disclosure (i.e., time spent with host country natives during the stay) and a multiitem measure of outgroup evaluation. Finally, we included a measure of intergroup anxiety because previous research has identified reduced anxiety as the key mediating mechanism responsible for positive imagined contact effects in other domains (see Crisp et al., 2010; Crisp \& Turner, 2012). Our hypothesis was that imagined contact would reduce anxiety at the prospect of interacting with host country natives which, in turn, would be associated with a larger amount of time spent with the outgroup and with improved evaluation of this group.

\section{Method}

\section{Participants and Procedure}


IMAGINED CONTACT AND INTERCULTURAL COMMUNICATION

Participants were 37 Italian students (15 females) who would soon depart for a university exchange program ${ }^{2}\left(M_{\mathrm{age}}=22\right.$ years $)$, randomly allocated to the experimental (intervention) vs. control condition. Participants in the experimental condition were asked, approximately one month before their departure, to imagine a relaxed, comfortable and positive meeting with a stranger from the country they were directed to. As in Study 1, they had to imagine a detailed meeting from a third-person perspective by keeping eyes closed, before writing down what they had just imagined (see Crisp \& Turner, 2012). Dependent measures were administered with an online questionnaire within one month after participants' return in Italy (on average, the stay lasted 6.57 months, ranging from 4 to 12 months). Participants in the control condition only completed the final online questionnaire.

\section{Measures}

All items, unless otherwise indicated, were measured on a 5-step scale ( $1=$ not at all; $5=$ very $m u c h)$.

Intergroup anxiety. Four items assessed the extent to which participants felt four emotions (anxious, awkward, comfortable, confident) toward natives (Stephan \& Stephan, 1985) during their stay. Items were recoded so that higher scores reflected more anxiety toward natives, and were then averaged in a single index of intergroup anxiety (alpha=.72).

Outgroup evaluation. Natives were evaluated on six items, based on the scale by Wright, Aron, McLaughlin-Volpe and Ropp (1997). Specifically, they were asked to indicate the degree to which they felt admiration, contempt, hostility, warmth, positivity, trust toward natives. After being recoded so that higher scores reflected more 
IMAGINED CONTACT AND INTERCULTURAL COMMUNICATION

positive intergroup attitudes, items were combined in a single index of positive outgroup evaluation (alpha $=.71)$.

Time spent with the outgroup. We used one item, asking the amount of time spent with friends formed among natives during the stay. The 5-step scale ranged from 1 (very small amount of time) to 5 (very large amount of time).

To control that the effects of the manipulation were specific to country natives and not other relevant groups, we also assessed (with the same items) anxiety toward (alpha=.72), evaluation of (alpha=.76), time spent with other exchange-program students.

\section{Results}

Means and standard deviations in the two conditions are presented in Table 2; correlations among variables are shown in Table 3. As can be seen in Table 3, experimental condition $(1=$ imagined contact; $0=$ control $)$ was negatively associated with intergroup anxiety, $r=-.32, p=.051$, whereas it was uncorrelated with outgroup evaluation and time spent with outgroup, $r \mathrm{~s}=.00$ and $.05, p \mathrm{~s}=.976$ and .755 , respectively. Moreover, intergroup anxiety was negatively associated with outgroup evaluation, $r=-.48, p=.002$, and with time spent with the outgroup, $r=-.34, p=.036$. Finally, outgroup evaluation and time spent with the outgroup were positively correlated, $r=.44, p=.006$.

Table 2

Table 3 
IMAGINED CONTACT AND INTERCULTURAL COMMUNICATION

To test hypotheses, we conducted a path analysis with observed variables (LISREL 8.7; Jöreskog \& Sörbom, 2004). In the tested model, experimental condition served as the predictor; intergroup anxiety was the mediating variable; time spent with the outgroup and its evaluation were the dependent variables. As predicted the model, represented in Figure 1, provided a good fit to the data: $\chi^{2}(2)=1.39, p=.50$; RMSEA $\cong$ $.00 ; \mathrm{SRMR}=.054 ; \mathrm{CFI}=1.00(\mathrm{Hu} \&$ Bentler, 1999). As can be noted, imagined contact reduced intergroup anxiety, $\beta=-.32, p=.051$; in turn, reduced anxiety was associated with increased time spent with the outgroup, $\beta=-.34, p=.037$, and with improved outgroup evaluation, $\beta=-.48, p=.002$. The indirect effect, calculated with bootstrapping procedures, was significant (95\% BCa confidence-interval ranging from .045 to .715 , for time spent with the outgroup, and from .030 to .307 , for outgroup evaluation). ${ }^{3}$

Figure 1

Notably, the manipulation did not affect anxiety toward, time spent with, and evaluation of other exchange-program students, $p s>.26$. Thus, effects observed were specific to relations with host country nationals, and not due to a generalized sociability promoted by the mental simulation task.

\section{General Discussion}

In two studies we showed that imagined contact, a mental simulation technique designed to facilitate social relations, positively influenced communication between international students and host country natives. In Study 1, imagined contact increased 
IMAGINED CONTACT AND INTERCULTURAL COMMUNICATION

self-disclosure toward and evaluation of country natives among international students who just arrived in their host country. In Study 2, an evaluation of an experimental field intervention showed that the mental simulation task affected a self-reported measure of self-disclosure toward natives during the stay and their evaluation via reduced intergroup anxiety. Notably, dependent variables in Study 2 were assessed, on average, more than seven months after the experimental intervention.

These findings provide first evidence for the effectiveness of imagined contact in improving relations between international students and host societies. The results of this research, in line with previous studies, also confirm the robustness of imagined contact effects (see Miles \& Crisp, 2014) by adopting a longitudinal experimental design (Study 2). Previous research has already demonstrated that imagined contact has long-lasting effects (e.g., Husnu \& Crisp, 2010; Vezzali, Capozza, Stathi, \& Giovannini, 2012). For instance, Vezzali et al. (2013) demonstrated that the effects of imagined contact can last up to two weeks. Our second study here considerably extends the longevity of the effects of imagined contact by showing that the mental simulation task can have an impact over the course of some months, rather than just weeks. We note, however, that this longer term impact of imagined contact was indirect; that is, there was no direct effect on outgroup evaluation and time spent with the outgroup (see Table 2). A possible explanation for this is that the passage of time weakened the original imagined contact effect. Alternatively, there might be unidentified suppressors, not controlled in our study, that balanced the beneficial indirect effect of the intervention via lower anxiety. If this interpretation is correct, the resulting consequence is that the power of imagined contact to alter intergroup behavior may be somewhat reduced. Further 
research is needed in order to better understand the trajectory of emotional and behavioral change following an imagined contact intervention.

In both studies, imagined contact was successful for the minority group, represented by international students in the host country. It should be noted that previous evidence reveals that imagined contact may be especially effective for majority groups. Stathi and Crisp (2008, Study 1) found that a positive imagined contact session fostered projection of positive traits to the outgroup among Mestizos (majority group), but not among Indigenous people (minority group) in Mexico. However, the minority group examined by Stathi and Crisp was of low status, in a context of long history of relations based on differences in status, language, way of life and traditions, opportunities in education and employment, with the majority group. In other words, the minority ethnic group studied by Stathi and Crisp was a priori defined by its minority status and a rather stigmatized identity. In contrast, the context in which international students are seen has no a history of inequality or conflict and the acquired identity is for a short period, corresponding to their stay abroad. Thus, their relations with majority host country members are far less conflictual than those characterizing long-lasting relations between ethnic groups with unequal status. In addition, participants in our studies completed the imagined contact manipulation just after their arrival (Study 1) or even before leaving the home country (Study 2), so a minority status identity was not salient at that point. Possibly, the imagined contact intervention helped these participants establish a smooth transition to the host country and eventually perceive their group identity as of similar status to that of host country members. Such positive conditions may explain why imagined contact was successful among the specific type of minority group considered in our studies. However, it is possible that, as shown by 
IMAGINED CONTACT AND INTERCULTURAL COMMUNICATION

Stathi and Crisp, imagined contact is less powerful in changing intergroup attitudes among stigmatized minority groups with a history of conflict with the majority group.

These results can be of critical importance to practitioners and have important implications for educational institutions looking to enhance the quality of experience of their intercultural programs. This is especially true when considering that attitudes toward host country members typically worsen after the exchange (Stroebe et al., 1988). In these cases, since creating structured direct contact sessions may be unpractical, it is crucial to identify strategies that foster more positive cross-group experiences. Sessions of imagined contact immediately before leaving and/or soon after students' arrival in the country of destination can facilitate contact between international students and host country natives which, once initiated, will foster more positive intergroup relations (Stangor et al., 1996). Importantly, increasing positive intercultural experiences has beneficial effects both for host members and for the hosted group. For instance, Simonton (1999) found in the Japanese context that foreign influence was positively associated with the number of eminent individuals in a generation. Sassenberg and Matschke's (2010) results indicate that exchange students were able to develop a richer self-concept (which incorporated the host society). More broadly, research from disparate literature has demonstrated that positive exposure to multicultural diversity and living abroad has beneficial consequences that, in addition to improving intergroup relations and fostering the desire for positive social change, extend to many different outcomes related to psychological functioning (Schwarzer, Bowler, \& Rauch, 1985), creativity and flexible thought (Maddux, Adam, \& Galinsky, 2010), cognitive development (Bowman, 2010), educational outcomes (Gurin, Dey, Hurtado, \& Gurin, 2002; for an extensive review, see Crisp \& Turner, 2011). 
IMAGINED CONTACT AND INTERCULTURAL COMMUNICATION

We acknowledge some limitations in the studies we have presented. First, in Study 2 we used a self-reported subjective behavioral measure of self-disclosure, rather than an objective measure assessing the actual number of friendships formed with natives during the stay. In future research we advocate the use of an objective measure of cross-group friendships. This would permit stronger conclusions about the effectiveness of imagined contact in promoting intercultural communication between international students and host country members. Second, future studies should consider additional samples of international students (e.g., high school students) in order to add ecological validity to the present results. Third, one must always be careful to consider the possibility of demand characteristics. For instance, it is possible that in Study 2 participants may have remembered the imagined contact sessions of some months before and guessed the study purposes, modifying their responses accordingly. However, previous research has directly tested for the impact of demand characteristics and found no evidence that it drives imagined contact effects (e.g., Turner \& Crisp, 2010; Turner \& West, 2012). Notably, the recent meta-analysis by Miles and Crisp (2014) also found a robust impact of imagined contact on implicit measures of both attitudes and behavior. That imagined contact can impact such implicit measures reduces any concern that its effects are due to demand. In addition, in Study 2 especially, participants would not only have had to recall the imagined contact task from many months before, but guess the direction of the predicted effect, and then be motivated to confirm (rather than disconfirm) this hypothesis; a range and complexity of variables that reduce any possible impact of demand. Finally, in Study 2, an explanation of effects merely based on demand characteristics cannot account for the nonsignificant direct effect of the experimental manipulation on outgroup evaluation 
and time spent with the outgroup. Despite these reasons for confidence, however, as a general point we would advise future studies to use dependent measures that are less likely to be open to demand-based critiques.

Given that the main aim of international exchange student programs is to increase mutual intercultural understanding between individuals and that cultural diversity experiences have broad positive effects, but also taking into consideration the challenges that exchange students face in the host society, we believe that actively fostering the development of smooth relations between students involved in exchange programs and host country members should be a primary and strategic aim for universities. Our research demonstrates that imagined contact can be an effective strategy encouraging intercultural communication and promoting the integration of exchange students in the host society, by creating the basis for all parties involved in the exchange to maximally benefit from the experience of cultural diversity. 


\section{Footnotes}

1. There were 25 exchange students from Spain, 4 from Turkey, 2 from Germany and Hungary, 1 from Austria, France, The Netherlands, UK, 3 missing.

2. The countries of destination of participants in the control condition were: Belgium (1 participant), Denmark (1 participant), France (7 participants), Germany (4 participants), Lithuania (1 participant), Portugal (1 participant), Spain (3 participants), UK (4 participants). The countries of destination of participants assigned to the experimental condition were: Austria (1 participant), Denmark (3 participants), Germany (1 participant), Poland (1 participant), Spain (4 participants), Sweden (2 participants), Turkey (1 participant), UK (2 participants).

3. Immediately prior to being allocated to conditions (and thus, before participants in the experimental condition completed the imagined contact task), approximately one month before their departure, participants completed an online questionnaire assessing initial evaluation of natives (a feeling thermometer was used) and prior number of friends among country natives. In the final questionnaire, administered after their return, participants reported length of stay along with demographic information (age, gender). We conducted additional analyses by running a path model identical to that shown in Figure 1, showing that effects remain significant when controlling for the effects these variables. Specifically, when the control variables were accounted for, experimental condition was negatively associated with intergroup anxiety, $\beta=-$ $.41, p=.027$; in turn, reduced anxiety was associated with increased time spent 


\section{IMAGINED CONTACT AND INTERCULTURAL COMMUNICATION}

with the outgroup, $\beta=-.38, p=.038$, and with improved outgroup evaluation, $\beta$ $=-.41, p=.009$. 
IMAGINED CONTACT AND INTERCULTURAL COMMUNICATION

\section{Acknowledgments}

We would like to thank the Students Mobility Office and the Exchange Erasmus

Student Network of the University of Modena and Reggio Emilia for their help in the organization and realization of the research. We are also grateful to Gaia Davolio, Laura De Zorzi Poggioli and Maria del Sol Omedas for their collaboration in data collection. 


\section{References}

Allport, G. W. (1954). The nature of prejudice. New York, NY: Addison-Wesley.

Benet-Martínez, V., Lee, F., \& Leu, J. (2006). Biculturalism and cognitive complexity: Expertise in cultural representations. Journal of Cross-Cultural Psychology, 37, 386-407. doi: 10.1177/0022022106288476

Bowman, N. A. (2010). College diversity experiences and cognitive development: A meta-analysis. Review of Educational Research, 80, 4-33. doi:

$10.3102 / 0034654309352495$

Crisp, R. J., \& Husnu, S. (2011). Attributional processes underlying imagined contact effects. Group Processes and Intergroup Relations, 14, 275-287. doi: $10.1177 / 1368430210390721$

Crisp, R. J., Husnu, S., Meleady, R., Stathi, S., \& Turner, R. N. (2010). From imagery to intention: A dual route model of imagined contact effects. European Review of Social Psychology, 21, 188-236. doi: 10.1080/10463283.2010.543312

Crisp, R. J., \& Turner, R. N. (2009). Can imagined contact interactions produce positive perceptions? Reducing prejudice through simulated social contact. American Psychologist, 64, 231-240. doi: 10.1037/a0014718

Crisp, R. J., \& Turner, R. N. (2011). Cognitive adaptation to the experience of social and cultural diversity. Psychological Bulletin, 137, 242-266. doi: $10.1037 / \mathrm{a} 0021840$

Crisp, R. J., \& Turner, R. N. (2012). The imagined contact hypothesis. In J. M. Olson \& M. P. Zanna (Eds.), Advances in experimental social psychology (pp. 125-182). Orlando, FL: Academic Press. 
IMAGINED CONTACT AND INTERCULTURAL COMMUNICATION

Gurin, P., Dey, E. L., Hurtado, S., \& Gurin, G. (2002). Diversity and higher education: Theory and impact on educational outcomes. Harward Educational Review, 72, $330-366$.

Haddock, G., Zanna, M. P., \& Esses, V. M. (1993). Assessing the structure of prejudicial attitudes: The case of attitudes toward homosexuals. Journal of Personality and Social Psychology, 65, 1105-1118. doi: 10.1037/00223514.65.6.1105

Hodson, G., Hewstone, M. (Eds.) (2013). Advances in intergroup contact. New York, NY: Psychology press.

Hu, L., \& Bentler, P. M. (1999). Cutoff criteria for fit indexes in covariance structure analysis: Conventional criteria versus new alternatives. Structural Equation Modeling, 6, 1-55. doi: 10.1080/10705519909540118

Husnu, S., \& Crisp, R. J. (2010). Elaboration enhances the imagined contact effect. Journal of Experimental Social Psychology, 46, 943-950. doi: 10.1016/j.jesp.2010.05.014

Husnu, S., \& Crisp, R. J. (2011). Enhancing the imagined contact effect. Journal of Social Psychology, 151, 113-116. doi: 10.1080/00224541003599043

Jöreskog, K. G., \& Sörbom, D. (2004). LISREL 8.7 for Windows [Computer Software]. Lincolnwood, IL: Scientific Software International, Inc.

Klineberg, O., \& Hull, W. F. (1979). At a foreign university: An international study of adaptation and coping. New York, NY: Praeger.

Maddux, W. W., Adam, H., \& Galinsky, A. D. (2010). When in Rome...Learn why the Romans do what they do: How multicultural learning experiences facilitate 
IMAGINED CONTACT AND INTERCULTURAL COMMUNICATION

creativity. Personality and Social Psychology Bulletin, 36, 731-741. doi:

$10.1177 / 0146167210367786$

McGuire, W. J., McGuire, C. V., Child, P., \& Fujioka, T. (1978). Salience of ethnicity in the spontaneous self-concept as a function of one's ethnic distinctiveness in the social environment. Journal of Personality and Social Psychology, 36, 511520. doi: 10.1037/0022-3514.36.5.511

Miles, E., \& Crisp, R. J. (2014). A meta-analytic test of the imagined contact hypothesis. Group Processes and Intergroup Relations, 17, 3-26. doi:10.1177/1368430213510573.

Paige, R. M. (1990). International students: Cross-cultural psychological perspectives. In R. W. Brislin (Ed.), Applied cross-cultural psychology: Cross-cultural research and methodology series (pp. 367-382). Newbury Park, CA: Sage.

Pedersen, P. B. (1991). Counseling international students. Counseling Psychologist, 19, 10-58. doi: 10.1177/0011000091191002

Pettigrew, T. F., \& Tropp, L. (2011). When groups meet: The dynamics of intergroup contact. New York, NY: Psychology Press.

Sassenberg, K., \& Matschke, C. (2010). The impact of exchange programs on the integration of the hostgroup into the self-concept. European Journal of Social Psychology, 40, 148-159. doi: 10.1002/ejsp.621

Schwarzer, R., Bowler, R., \& Rauch, S. (1985). Psychological indicators of acculturation: Self-esteem, racial tension and inter-ethnic contact. In L. Ekstrand (Ed.), Ethnic minorities and immigrants in a cross-cultural perspective (pp. 211229). Lisse, the Netherlands: Swets and Zeitlinger. 
IMAGINED CONTACT AND INTERCULTURAL COMMUNICATION

Sigalas, E. (2010). Cross-border mobility and European identity: The effectiveness of intergroup contact during the Erasmus year abroad. European Union Politics, 11, 241-265. doi: 10.1177/1465116510363656

Simonton, D. K. (1999). Origins of genius: Darwinian perspectives on creativity. New York, NY: Oxford University Press.

Spencer-Rodgers, J., \& McGovern, T. (2002). Attitudes toward the culturally different: The role of intercultural communication barriers, affective responses, consensual stereotypes, and perceived threat. International Journal of Intercultural Relations, 26, 609-631. doi: 10.1016/S0147-1767(02)00038-X

Stangor, C., Jonas, K., Stroebe, W., \& Hewstone, M. (1996). Development and change of national stereotypes and attitudes. European Journal of Social Psychology, 26, 663-675. doi: 10.1002/(SICI)1099-0992(199607)26:4<663::AIDEJSP778>3.0.CO;2-6

Stathi, S., \& Crisp, R. (2008). Imagining intergroup contact promotes projection to outgroups. Journal of Experimental Social Psychology, 44, 943-957. doi:10.1016/j.jesp.2008.02.003

Stephan, W. G., \& Stephan, C. W. (1985). Intergroup anxiety. Journal of Social Issues, 41, 157-175. doi: 10.1111/j.1540-4560.1985.tb01134.x

Stroebe, W., Lenkert, A., \& Jonas, K. (1988). Familiarity may breed contempt: The impact of student exchange on national stereotypes and attitudes. In W. Stroebe, A. W. Kruglanski, D. Bar-Tal \& M. Hewstone (Eds.), The social psychology of intergroup conflict. Theory, research and applications (pp. 167-187). Berlin, Germany: Springer. 
IMAGINED CONTACT AND INTERCULTURAL COMMUNICATION

Turner, R. N., \& Crisp, R. J. (2010). Imagining intergroup contact reduces implicit prejudice. British Journal of Social Psychology, 49, 129-142. doi:

$10.1348 / 014466609 X 419901$

Turner, R. N., Hewstone, M., \& Voci, A. (2007). Reducing explicit and implicit outgroup prejudice via direct and extended contact: The mediating role of selfdisclosure and intergroup anxiety. Journal of Personality and Social Psychology, 93, 369-388. doi: 10.1037/0022-3514.93.3.369

Turner, R. N., \& West, K. (2012). Behavioural consequences of imagining intergroup contact with stigmatized outgroups. Group Processes and Intergroup Relations, 15, 193-202. doi:10.1177/1368430211418699

UKCOSA, (2004). International students in UK universities and colleges. Broadening our horizons. Report of the UKCOSA survey. http://www.ukcosa.org.uk/survey/report.pdf

Vezzali, L., Capozza, D., Giovannini, D., \& Stathi, S. (2012). Improving explicit and implicit intergroup attitudes using imagined contact: An experimental intervention with elementary school children. Group Processes and Intergroup Relations, 15, 203-212. doi: $10.1177 / 1368430211424920$

Vezzali, L., Capozza, D., Stathi, S., \& Giovannini, D. (2012). Increasing outgroup trust, reducing infrahumanization, and enhancing future contact intentions via imagined intergroup contact. Journal of Experimental Social Psychology, 48, 437-440. doi:10.1016/j.jesp.2011.09.008

Vezzali, L., Stathi, S., Crisp, R. J., Giovannini, D., Capozza, D., \& Gaertner, S. L. (2013). Imagined intergroup contact and common ingroup identity: An integrative approach. Manuscript submitted for publication. 


\section{IMAGINED CONTACT AND INTERCULTURAL COMMUNICATION}

Wright, S. C., Aron, A., McLaughlin-Volpe, T., \& Ropp, S. A (1997). The extended contact effect: Knowledge of cross-group friendships and prejudice. Journal of Personality and Social Psychology, 73, 73-90. doi: 10.1037/0022-3514.73.1.73 
IMAGINED CONTACT AND INTERCULTURAL COMMUNICATION

Tables

Table 1. Means and standard deviations for participants in the experimental and control conditions (Study 1).

\begin{tabular}{|c|c|c|c|c|c|c|c|}
\hline \multirow[b]{3}{*}{ Measure } & \multicolumn{4}{|c|}{ Condition } & \multirow[b]{3}{*}{$t$-test } & \multirow[b]{3}{*}{$p$-value } & \multirow[b]{3}{*}{ Cohen's $d$} \\
\hline & \multicolumn{2}{|c|}{ Experimental } & \multicolumn{2}{|c|}{ Control } & & & \\
\hline & $M$ & $S D$ & $M$ & $S D$ & & & \\
\hline $\begin{array}{l}\text { Self-disclosure } \\
\text { toward the outgroup }\end{array}$ & 3.74 & 0.87 & 3.14 & 0.97 & 2.03 & 0.049 & 0.64 \\
\hline Outgroup evaluation & 86.32 & 8.31 & 77.14 & 12.70 & 2.67 & 0.011 & 0.84 \\
\hline
\end{tabular}


IMAGINED CONTACT AND INTERCULTURAL COMMUNICATION

Table 2. Means and standard deviations for participants in the experimental and control conditions (Study 2).

\section{Condition}

\section{Experimental Control}

\begin{tabular}{lccccccc} 
Measure & $M$ & $S D$ & $M$ & $S D$ & $t$-test & $p$-value & Cohen's $d$ \\
\hline Intergroup anxiety & 1.96 & 0.65 & 2.51 & 0.90 & 2.02 & 0.051 & 0.68
\end{tabular}

$\begin{array}{llllllll}\text { Outgroup evaluation } & 4.07 & 0.43 & 4.08 & 0.44 & 0.03 & 0.976 & 0.01\end{array}$

Time spent with the outgroup

$\begin{array}{lllllll}3.00 & 1.25 & 2.86 & 1.32 & 0.32 & 0.755 & 0.11\end{array}$

Note. The response scale for all measures ranged from 1 to 5 . 
IMAGINED CONTACT AND INTERCULTURAL COMMUNICATION

Table 3. Correlations among variables included in the path model (Study 2).

\begin{tabular}{lcccc}
\hline & 1 & 2 & 3 & 4 \\
\hline $\begin{array}{l}\text { 1. Condition } \\
\quad(1=\text { experimental, } 0=\text { control })\end{array}$ & - & & & \\
2. Intergroup anxiety & $-.32^{*}$ & - & & \\
3. Outgroup evaluation & .00 & $-.48^{* *}$ & - & \\
4. Time spent with the outgroup & .05 & $-.34^{*}$ & $.44^{* *}$ & - \\
\hline
\end{tabular}
$* p \leq .05 . * * p<.01$. 